\title{
Entender la Bioquímica en Enfermería partiendo de casos problemas
}

\section{Understanding Biochemistry in Nursing from cases}

CRISTINA B. TOUS RIVERA

https://orcid.org/0000-0002-3590-1904

Universidad de Sevilla. Centro

Universitario de Enfermería Cruz Roja

ctous@us.es

Fecha de recepción: 24/11/2019

Fecha de aceptación: 26/11/2019

DOI: http://dx.doi.org/10.12795/9788447221912.038 Pp.: 863-885 


\section{Resumen}

Se ha realizado un ciclo de mejora en el aula (CIMA) en la asignatura de Bioquímica y Biología Molecular del el primer curso del Centro Universitario de Enfermería Cruz Roja, adscrito a la Universidad de Sevilla. En esta asignatura ya se ha llevado a cabo otros ciclos de mejora, por lo que en este curso, además de realizar mejoras en base a las experiencias adquiridas en el grupo grande se han implantado mejoras en los grupos pequeños. En diferentes sesiones con un total de 14 horas, se han analizado el resultado de los ciclos de mejora obteniéndose un resultado satisfactorio en cada uno de ellos.

Palabras clave: Biochemistry and Molecular Biology, Degree in Nursing, docencia universitaria, experimentación docente universitaria.

\section{Abstract}

A cycle of improvement in the classroom (CIMA) has been carried out in the subject ofBiochemistry and Molecular Biology of the first course of the University Center for Red Cross Nursing, attached to the University of Seville. In this subject, other cycles of improvement have already been carried out, so in addition to making improvements based on the experiences gained in the large group, improvements have been made in the small groups. In different sessions with a total of 14 hours, the result of the improvement cycles have been analyzed obtaining a satisfactory result in each of them.

Key words: Biochemistry and Molecular Biology, Degree in Nursing, university teaching, university teaching experimentation.

Jornadas de Formación e Innovación Docente del Profesorado | № 2 (2019)

Esta obra se distribuye con la licencia Creative Commons 


\section{Descripción del contexto}

La asignatura donde se ha realizado el ciclo de mejora es "Bioquímica y Biología Molecular" del primer curso del Grado de Enfermería, en el Centro Universitario de Enfermería Cruz Roja, adscrito a la Universidad de Sevilla. Es una asignatura cuatrimestral de 6 créditos ECTS, que se imparte en el primer cuatrimestre del curso y es de formación básica. La docencia presencial se distribuye en 50 horas de clases teóricas y 10 horas de clases prácticas. Los alumnos son en su mayoría de bachillerato de ciencia, aunque hay una proporción alta que proceden de ciclos formativos teniendo un nivel inferior en conocimientos de biología. El grupo está formado por aproximadamente 87 alumnos, de los cuales suelen asistir a clase teóricas 73 de ellos. Las clases prácticas se dividen en 5 grupos de unos 16 alumnos cada uno. El aula donde se desarrollan las clases es grande y espaciosa pero no dispone de un mobiliario adecuado para la movilidad del alumnado.

\section{Diseño previo del CIMA}

\section{Mapas de contenido y problemas}

En el curso anterior se plateó un nuevo ciclo de mejora, que correspondían a 4 temas, referentes al bloque de Estructura y función de las Proteínas. En esta ocasión, se han incorporado dos nuevos ciclos de mejora, además de perfeccionar el ciclo anterior. En total los ciclos de mejora abarcarán 5 temas y 2 seminarios con una duración de 14 horas. Los ciclos comenzarán el 29 de octubre y finalizarán en 12 de Noviembre de 2019.

El primer CIMA se realiza en una sesión de 2 horas de clase, en las cuales se imparte el tema referente a las

Jornadas de Formación e Innovación Docente del Profesorado | № 2 (2019)

Esta obra se distribuye con la licencia Creative Commons 
Enfermedades Moleculares. Este tema es clave para que vean la relación que existe entre las enfermedades, su causa molecular y la herencia o no de un individuo a otro. En la figura 1 se muestra el mapa de contenidos. En la figura 1 se expone el mapa de contenidos, con los conceptos fundamentales: negrita, los contenidos conceptuales: negro, los contenidos procedimentales: rojo, y las flechas son relaciones entre contenidos.

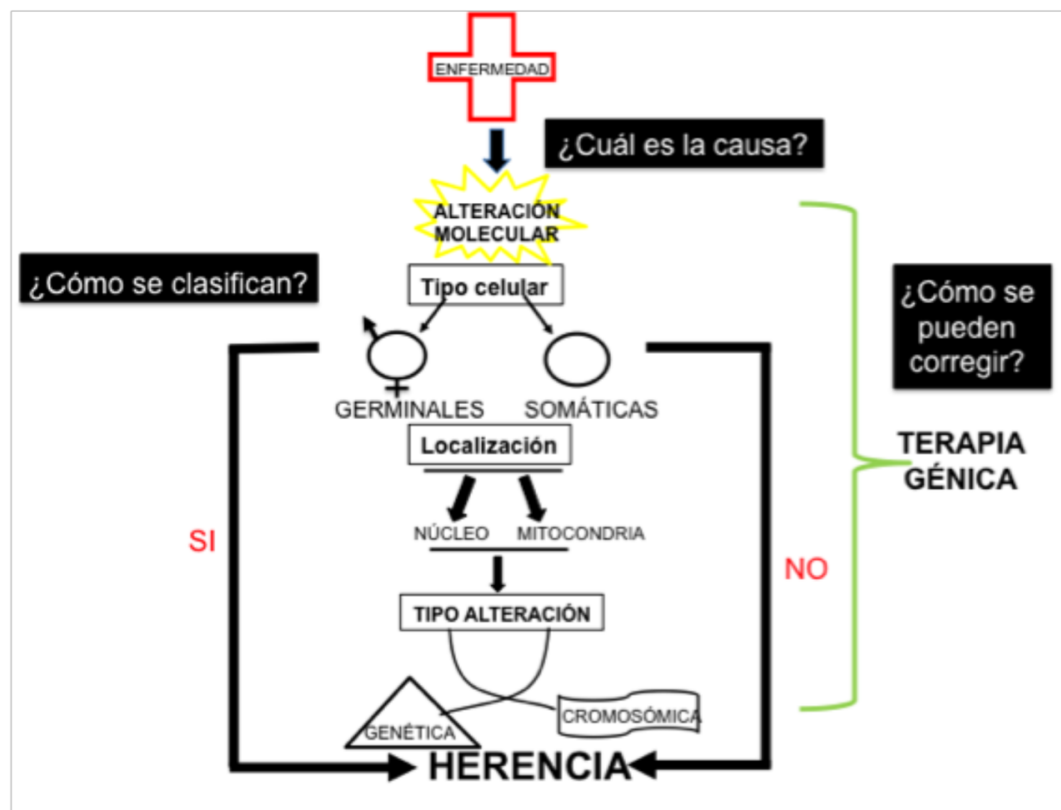

Figura 1: Mapa de contenidos.

A continuación, se detallan las preguntas clave:

El estudio de una enfermedad se realiza desde un juicio clínico y molecular. Este último nos permite clasificarlas permitiendo un mejor y más acertado diagnóstico.

A. ¿Cómo clasificaríamos las siguientes enfermedades según si afectan a tejidos o células o si tienen alteraciones moleculares? ¿Cómo es su herencia?

- Albinismo o Fibrosis quística

- Enfermedad de Corea de Huntington

- Distrofia muscular de Duchenne

- Sindrome de X-frágil

Jornadas de Formación e Innovación Docente del Profesorado | № 2 (2019)

Esta obra se distribuye con la licencia Creative Commons Reconocimiento-NoComercial-SinObraDerivada Internacional (CC BY-NC-ND 4.0.) 
B. Hay enfermedades cuya afectación molecular es a nivel cromosómico. ¿Influye la localización? ¿Por qué?

C. ¿Sabrías decir como se originan las enfermedades cromosómicas? ¿Cómo conocemos la enfermedad de la trisomía del par 21?, ¿sabrías decir alguna característica molecular?

D. La Terapia génica se conoce como la inserción de elementos funcionales en el genoma de un individuo, ¿sabrías decir por que se utiliza esta técnica?,¿en que casos se realiza?

El segundo CIMA corresponde al bloque temático de Estructura y función de las Proteínas, con 8 horas. Se corresponde con el CIMA realizado el año anterior, pero mejorando las deficiencias encontradas durante su realización, que se expondrán más adelante. En la figura 2, se expone el mapa de contenidos, donde los conceptos fundamentales los marca el color de cada flecha. La Estrella roja determina los conceptos a adquirir (Estructura de las proteínas, aminoácidos y enlace peptídico, función de las proteínas). La Estrella amarilla indica conceptos procedimentales (relacionar la función de una proteína con su estructura). La Estrella azul indica valores (ser consciente de la importancia de la proteínas en el ser vivo).

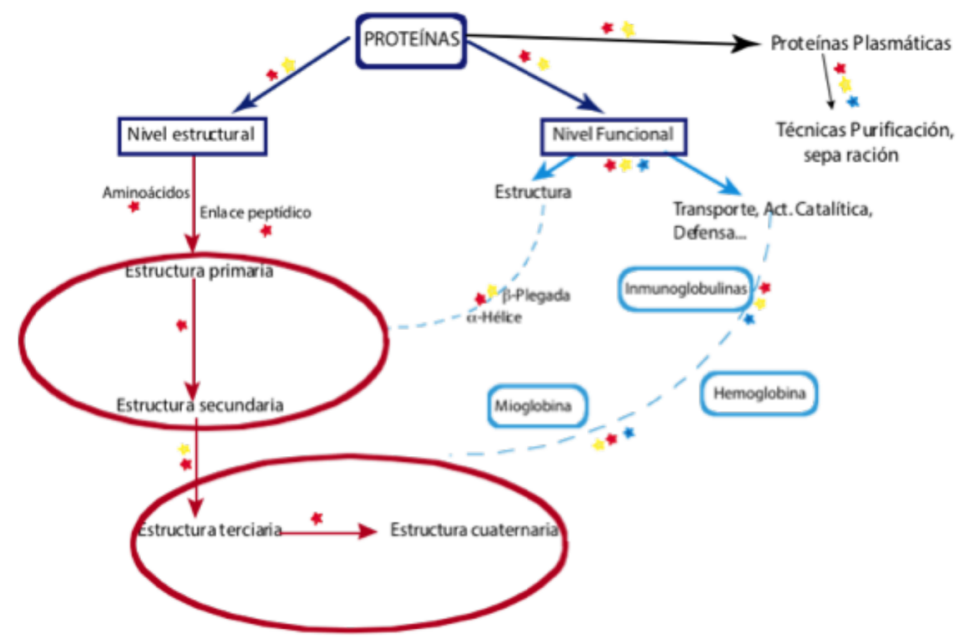

Figura 2: Mapa de contenidos

Jornadas de Formación e Innovación Docente del Profesorado | № 2 (2019)

Esta obra se distribuye con la licencia Creative Commons 
Una de las mejoras propuestas para este CIMA es la reestructuración de las preguntas del módulo de proteínas. Las preguntas claves, fueron el curso pasado, demasiadas largas y llevaban a confusión e incluso a repetición de conceptos, por ello este curso las he modificando acortando y siendo mas concisa respecto a los conceptos fundamentales que se quieren transmitir.

1. ¿Qué es una proteína?, ¿Cómo las clasificarías, por su función, por su estructura, por ambas?, Razónalo.

2. ¿Cuál es la función y clasificación de la unidad mas pequeña que forman a las proteínas? El conjunto de esta unidad forman niveles estructurales, ¿cómo se van formando éstos niveles? Describe los niveles que hay hasta llegar a la estructura del colágeno.

3. ¿La Mioglobina y la Hemoglobina tienen igual función?, Enumera las similitudes y diferencias.

4. El plasma sanguíneo está formado por muchas proteínas con diversas funciones. ¿Sabrías explicar las mas abundantes e importantes? ¿Qué proteína implicada en la defensa del organismo encontramos en el plasma?

5. El estudio de las proteínas nos ayudan a identificar enfermedades o patologías desconocidas e incluso seguir enfermedades ya conocidas. ¿Existen técnicas de laboratorio que nos permiten obtener dichas proteínas?. ¿Cuáles son las técnicas mas conocidas?.

El tercer CIMA se realiza en dos seminarios que abarcan 4 horas de docencia. En este caso se analizará un artículo de investigación que haga referencia a algunos conceptos importantes de la bioquimica. Hasta ahora, en los seminarios (grupo pequeño) se abordaban temas de bioquímica básicos que no se daban en clase pero que ayudaban a integrar mejor los conceptos. Los estudiantes preparaban al azar los temas y tenían unos 20 minutos para explicarlos a los demás compañeros. Tras su exposición, había una tanda de preguntas para resolver las dudas que se planteaban. En este CIMA se pretende trabajar

Jornadas de Formación e Innovación Docente del Profesorado | № 2 (2019)

Esta obra se distribuye con la licencia Creative Commons 
los conceptos de bioquímica desde artículos de revista internacional actuales. El factor que más les va a limitar es el nivel de inglés, aunque, un número elevado de alumnos tienen nivel de B2 y C1. Como he hecho hasta ahora, en el campus virtual les proporciono los artículos que se tendrán que preparar.

Los artículos son los siguientes:

1. Biological Determinants of Health: Genes, Microbes, and Metabolism Exemplars of Nursing Science.

2. Interacción de las vías de señalización intracelulares participantes en la proliferación celular: potencial blanco de intervencionismo terapéutico.

3. Transcription-replication conflicts: how they occur and how they are resolved.

4. An introduction to immunology and immunopathology.

\section{Modelo metodológico posible y secuencia de actividades programada.}

El modelo metodológico a seguir en grupo grande, es el mismo que se llevó a cabo en el curso anterior. El modelo metodológico que considero ideal, es realizar una metodología de trabajo colaborativa en clase, con un previo trabajo individualizado en casa. En la figura 3 se representa el modelo metodológico del Cima 1 y del 2. Referir que en ambos casos se realiza el mismo modelo metodológico (A). Tan sólo en el CIMA 1 se incluye el modelo metodológico-B en la última sesión, donde se realiza el juego de Pasapalabra.

Jornadas de Formación e Innovación Docente del Profesorado | № 2 (2019)

Esta obra se distribuye con la licencia Creative Commons 


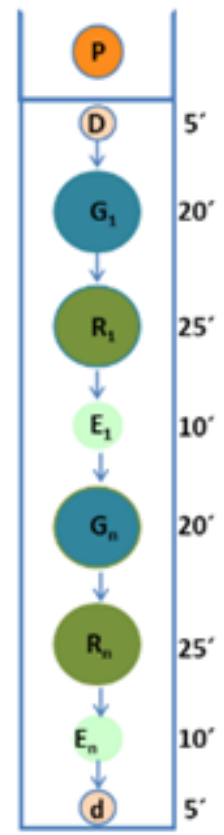

A

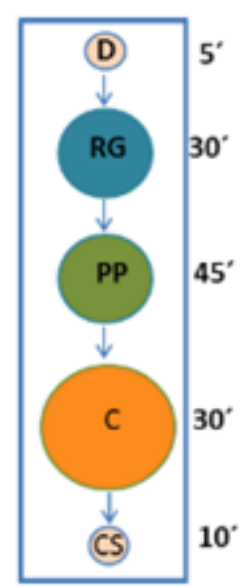

B

Figura 3. Representación del modelo metodológico CIMA 1 y 2.

Para las 2 sesiones de grupo pequeño (CIMA 3) el modelo metodológico que se pretende seguir es un modelo mucho más cooperativo. Los artículos se les dará con antelación (campus virtual), ellos deben leerlos y entender, obteniendo de cada uno de ellos unos objetivos y conclusiones. Las dudas que les surjan, deberán llevarlas anotadas para intentar resolverlas en clase. Una vez en clase y en subgrupos de 4 estudiantes (TG), deberán entre todos resolver las dudas $(\mathrm{Rd})$ que tengan y para ello dispondran de 40 minutos (tendrán que escribir dichas respuestas). El profesor irá por los distintos grupos (García, Porlán y Navarro, E., 2017; Amador, Monreal y Marco, 2001). Tras ese tiempo 2 miembros del subgrupo A y del B expondrán un resumen del artículo 1. Tras la exposición los demás alumnos podrán aportar información de la que no se haya

Jornadas de Formación e Innovación Docente del Profesorado I № 2 (2019)

Esta obra se distribuye con la licencia Creative Commons 
hablado o de plantear dudas que no se hayan resuelto. Para la explosión y resolución de dudas dispondrán de 20 minutos. Para los demás artículos se procederá de la misma forma. Asi en 2 horas de clase pueden trabajar 2 artículos entre todos. En la figura 4, representa el modelo metodológico del CIMA 3, donde TI: Trabajo Individual, TG: trabajo grupo pequeño, Rd: Resolución de dudas.

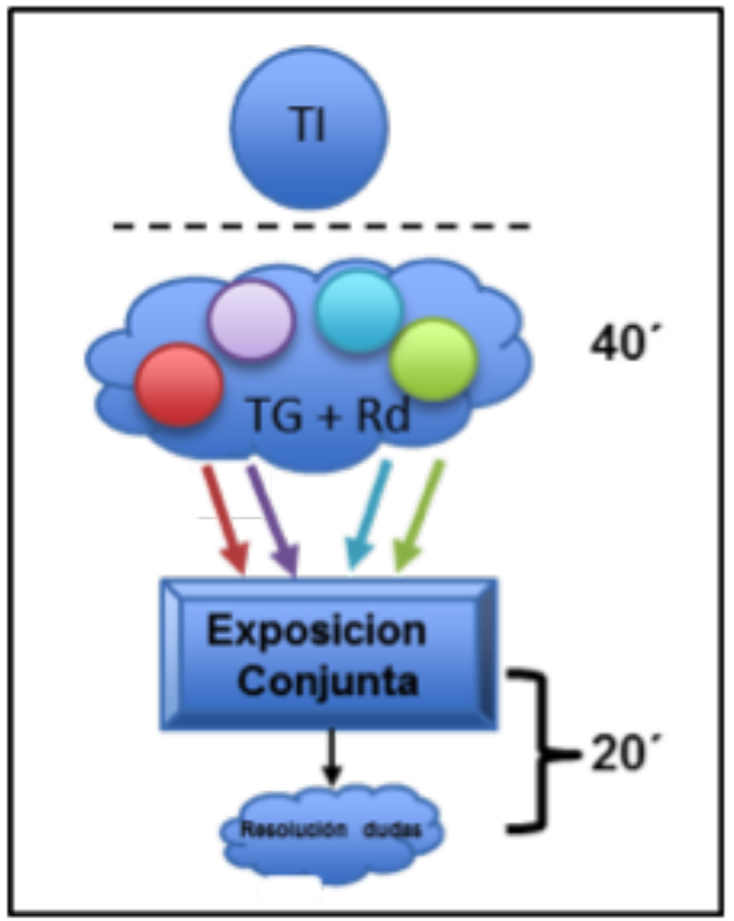

Figura 4. Representación del modelo metodológico CIMA 3.

Jornadas de Formación e Innovación Docente del Profesorado | № 2 (2019)

Esta obra se distribuye con la licencia Creative Commons Reconocimiento-NoComercial-SinObraDerivada 


\section{Secuencia de actividades}

En la tabla 1, se expone la duración en minutos de cada actividad realizada por cada hora (total 10 horas):

Tabla 1. Temporalización y actividades CIMA 1 y 2.

\begin{tabular}{|c|c|c|}
\hline & CIMA 1 (1 sesión) y 2 ( 4 sesiones) & Min \\
\hline $\mathbf{P}$ & $\begin{array}{l}\text { - En la clase anterior al inicio de la clase de mejora se les pasará un } \\
\text { cuestionario con las preguntas que mas tarde trabajarán en casa. } \\
\text { Se les informa que es individual y que no tendrá ningún carácter } \\
\text { evaluador. } \\
\text { - Las preguntas se pondrán en el campus virtual. Se les comenta } \\
\text { que deben profundizar en sus respuestas, que una respuesta de tan } \\
\text { solo } 3 \text { líneas no se considera suficiente. }\end{array}$ & $20^{-}$ \\
\hline D & $\begin{array}{l}\text { - Se comienza la clase dejando unos minutos para resolver dudas de } \\
\text { la clase anterior. Utilizo las imágenes y powerpoint para aclarar las } \\
\text { dudas. Si hay pocas preguntas, insistir en que miren lo dado el día o } \\
\text { semana anterior. }\end{array}$ & 5 \\
\hline G & $\begin{array}{l}\text { - Se reunirán en grupos de } 4 \text { para responder a la primera pregunta. } \\
\text { Deberán cada uno aportar la información que tengan para llegar } \\
\text { a una común. Elegirán un secretario que recoja la información. El } \\
\text { profesor estará entre los grupos para resolver dudas y ver como } \\
\text { interaccionan entre ellos (Finkel 2000). }\end{array}$ & $20^{-}$ \\
\hline $\mathbf{R}$ & $\begin{array}{l}\text { - Se piden voluntarios para que lean la respuesta a la primera } \\
\text { pregunta. Tras la participación de } 5 \text { o } 6 \text { grupos podrán ir aportando } \\
\text { ideas o conceptos que crean que deban cambiar o ampliar. La } \\
\text { participación del profesor consistirá en preguntar que añadirían } \\
\text { a las respuestas dadas para intentar generar un diálogo y que } \\
\text { lleguen a una respuesta común y consensuada. En la pizarra se irá } \\
\text { escribiendo esquemáticamente la información que aporten. }\end{array}$ & $25^{-}$ \\
\hline $\mathbf{E}$ & $\begin{array}{l}\text { - Tras los } 25 \text { minutos, les hago un breve resumen de la respuesta } \\
\text { que han ido construyendo, para afianzar los conocimientos } \\
\text { adquiridos y se ampliará la información si es necesario. Para ello } \\
\text { se empleará como soporte diapositivas de powerpoint. En las } \\
\text { explicaciones se profundizará en los contenidos teóricos que dan } \\
\text { respuesta a las preguntas planteadas. }\end{array}$ & $10^{-}$ \\
\hline $\mathbf{G}_{\mathbf{n}}$ & $\begin{array}{l}\text { - Se volverá a reunir en grupo y se pasará a responder la segunda } \\
\text { pregunta }\end{array}$ & $20^{-}$ \\
\hline
\end{tabular}

Jornadas de Formación e Innovación Docente del Profesorado | № 2 (2019)

Esta obra se distribuye con la licencia Creative Commons Reconocimiento-NoComercial-SinObraDerivada $\quad 4.0$ Internacional (CC BY-NC-ND 4.0.) 


\begin{tabular}{|c|c|c|}
\hline $\mathbf{R}_{\mathrm{n}}$ & $\begin{array}{l}\text { - Se pasará a responder la segunda pregunta planteada. (Igual se } \\
\text { procederá para todas las cuestiones). } \\
\text { - Se pedirán voluntarios para que lean sus respuestas y se animará } \\
\text { a los mas callados a que den su opinión. } \\
\text { - El profesor, tras } 3 \text { o } 4 \text { intervenciones, podrá ir esquematizando en } \\
\text { la pizarra las ideas que van dando, para que puedan ir siguiendo su } \\
\text { propio hilo conductor. }\end{array}$ & $25^{\prime}$ \\
\hline$E_{n}$ & $\begin{array}{l}\text { - Una vez hayan aclarada la respuesta, el profesor volverá a hacer } \\
\text { un resumen de las conclusiones y se ampliará la información mas } \\
\text { relevante. Para ello se utilizarán diapositivas en powerpoint. }\end{array}$ & $10^{-}$ \\
\hline \multirow[t]{2}{*}{ d } & $\begin{array}{l}\text { - Los últimos } 5 \text { min antes de finalizar, se recuerda que en la } \\
\text { siguiente sesión se van a responder las siguientes preguntas. Se les } \\
\text { anima a revisar lo que han respondido por si quieren incluir nueva } \\
\text { información o modificar algo. }\end{array}$ & $5^{\prime}$ \\
\hline & Última sesión del CMD 1 & \\
\hline $\begin{array}{l}\text { RG } \\
+ \\
\text { PP }\end{array}$ & $\begin{array}{l}\text { - Tras finalizar las cuestiones se hará un resumen general de todas } \\
\text { ellas. Se hará conjunto entre los estudiantes y el profesor. } \\
\text { Al terminar se les planteará hacer el juego de pasapalabras. }\end{array}$ & $75^{\prime}$ \\
\hline C & $\begin{array}{l}\text { - Tras termina el juego se les volverá a pasar el cuestionario inicial } \\
\text { para que vuelvan a rellenarlo con los conocimientos adquiridos en } \\
\text { estas } 4 \text { sesiones. }\end{array}$ & $30^{-}$ \\
\hline CS & $\begin{array}{l}\text { - Los últimos } 10 \text { min antes de finalizar la clase, se les pasará el } \\
\text { cuestionario de satisfacción. }\end{array}$ & $10^{-}$ \\
\hline
\end{tabular}

En la siguiente tabla se expone, la duración en minutos de cada actividad a realizar por cada hora (total 4 horas):

Tabla 2. Temporalización y actividades CIMA 3.

\begin{tabular}{|l|l|c|}
\hline & CIMA 3 (2 sesiones) & Min \\
\hline \hline $\mathbf{P}$ & $\begin{array}{l}\text { En el campus virtual, se le pondrá en PDF los artículos que tendrán } \\
\text { que trabajar }\end{array}$ & \\
\hline $\mathbf{G}$ & $\begin{array}{l}\text { - Se dividirán en subgrupos de 4. Cada uno aportará sus preguntas / } \\
\text { dudas e intentarán entre todos resolverlas. Deberán escribir las } \\
\text { respuestas para así entender mejor los artículos. El profesor estará } \\
\text { entre los grupos para resolver dudas y ver como interaccionan entre } \\
\text { ellos. }\end{array}$ & $40^{-}$ \\
\hline
\end{tabular}

Jornadas de Formación e Innovación Docente del Profesorado I № 2 (2019)

Esta obra se distribuye con la licencia Creative Commons Reconocimiento-NoComercial-SinObraDerivada $\quad 4.0$ Internacional (CC BY-NC-ND 4.0.) 


\begin{tabular}{|l|l|l|}
\hline PC & $\begin{array}{l}\text { - Dos miembros de dos subgrupos, de forma aleatoria explicarán a } \\
\text { los demás alumnos el articulo de la forma mas completa posible. Se } \\
\text { podrán ayudar de las imágenes de los artículos para que les sea a } \\
\text { todos más sencillo seguirles. }\end{array}$ & $15^{\prime}$ \\
\hline D & $\begin{array}{l}\text { - Por último, los demás alumnos podrá, hacer preguntas o incluir } \\
\text { algo que no se haya aclarado durante la exposición }\end{array}$ & $5^{-}$ \\
\hline & - En la siguiente hora, se procederá igual con el segundo artículo. & $60^{-}$ \\
\hline
\end{tabular}

\section{Cuestionario inicial y final}

En los CIMA 1 y 2 se realizan por parte de los estudiantes, unos cuestionarios iniciales y finales, necesarios para poder evaluar los conocimientos que tienen de la materia, antes y después a la actividad. Dichos cuestionarios están formados por las mismas preguntas que ya sen expuesto anteriormente en las preguntas claves.

En el caso del CIMA 3 de grupo pequeño, se les pasa un cuestionario que determine la capacidad de enfrentarse a otro idioma que no se el nativo, la capacidad de trabajo en grupo y su capacidad de improvisación. Dicho cuestionario se presenta a continuación:

1. ¿Tiene conocimientos sobre como analizar un artículo de investigación?

Valore de 1 (nada) a 5 (mucho) los conocimientos que tiene de esta pregunta

\begin{tabular}{|l|l|l|l|l|}
\hline 1. Nada & 2.Casi nada & 3. Algo & 4. Bastante & 5. Mucho \\
\hline & & & & \\
\hline
\end{tabular}

2. ¿Sabría obtener los conceptos fundamentales de un artículo científico?

Valore de 1 (nada) a 5 (mucho) los conocimientos que tiene de esta pregunta

\begin{tabular}{|l|l|l|l|l|}
\hline 1. Nada & 2.Casi nada & 3. Algo & 4. Bastante & 5. Mucho \\
\hline & & & & \\
\hline
\end{tabular}

Jornadas de Formación e Innovación Docente del Profesorado | № 2 (2019)

Esta obra se distribuye con la licencia Creative Commons 
3. ¿Podrías explicar junto a varios compañeros un tema específico sin antes hacer un reparto de dicho tema?

\begin{tabular}{|l|l|l|l|l|}
\hline 1. Nada & 2.Casi nada & 3. Algo & 4. Bastante & 5. Mucho \\
\hline & & & & \\
\hline
\end{tabular}

Al finalizar los tres CIMA se les pasó un cuestionario final de opiniones (preguntas abiertas) y satisfacción (preguntas cerradas con 5 opciones de respuesta), a modo de que describan lo que más les ha gustado del proceso de enseñanza-aprendizaje diferenciando CIMA 1 y 2 del CIMA 3 que es distinto. En dicho cuestionario se les preguntó por los aspectos que se podrían mejorar. Y por último que valoren su satisfacción con el proceso los CIMA 1 y 2 y con el CIMA 3. A continuación se presenta el cuestionario:

Valore su satisfacción con proceso de enseñanza-aprendizaje CIMA 1 y 2

\begin{tabular}{|l|l|l|l|l|}
\hline 1. Nada & 2.Casi nada & 3. Algo & 4. Bastante & 5. Mucho \\
\hline & & & & \\
\hline
\end{tabular}

Valore su satisfacción con proceso de enseñanza-aprendizaje CIMA 3

\begin{tabular}{|l|l|l|l|l|}
\hline 1. Nada & 2.Casi nada & 3. Algo & 4. Bastante & 5. Mucho \\
\hline & & & & \\
\hline
\end{tabular}

¿Qué aspectos de esta experiencia docente te gustaría que el profesor mantenga de ahora en adelante?

¿Qué aspectos de esta experiencia docente crees que sobran?

Valora tu satisfacción global.

\begin{tabular}{|l|l|l|l|l|}
\hline 1. Nada & 2.Casi nada & 3. Algo & 4. Bastante & 5. Mucho \\
\hline & & & & \\
\hline
\end{tabular}

Jornadas de Formación e Innovación Docente del Profesorado | № 2 (2019)

Esta obra se distribuye con la licencia Creative Commons Reconocimiento-NoComercial-SinObraDerivada $\quad 4.0$ Internacional (CC BY-NC-ND 4.0.) 


\section{Aplicación del CIMA}

\section{Resumen de las sesiones}

El primer CIMA tuvo una duración de 2 horas. La calse se inició dando 5 min para resolver dudas sobre la última clase que tuvimos. Tan sólo hubo una pregunta que resolví brevemente. Inmediatamente después, en 3 minutos, les expliqué la dinámica que ibamos a realizar y les resolví las dudas que le surgieron. Empezamos e hicieron los grupos de 4 alumnos bastante rápidos, a algunos los ayudé a ubicarse y empezaron a responder en grupo a la primera pregunta que se planteaba referente a Enfermedades Moleculares. Durante los 20 min que ellos estaban buscando un consenso para responer a la primera pregunta lo mas completa posible, el profesor estaba entre ellos observando el trabajo e intentando que las preguntas se las hicieran y respondieran entre ellos y no al profesor.

Tras el tiempo adjudicado, pasamos a responder entre todos a la primera cuestión. El profesor fue el moderador e iba haciendo un esquema, en la pizarra, de lo que ellos iban diciendo. Como primer error a ésta pregunta, los alumnos se basaron en analizar las características de cada una de las enfermedades nombradas, pero poco hablaron del tipo de herencia. Al final de las diferentes exposiciones el profesor realizó una pequeña aportación de los datos que faltaban.

Se prosiguió igualmente con las demás cuestiones. Como ya sabían como debian enfocar cada pregunta las demás fueron muchisimo mejor. Salieron de forma voluntaria para moderar y apuntar en la pizarra y fueron mejorando en confianza.

El cuestionario de finalización, se les pasó en los primeros 20 minutos de la clase de la semana siguiente.

Jornadas de Formación e Innovación Docente del Profesorado | № 2 (2019)

Esta obra se distribuye con la licencia Creative Commons 
El segundo CIMA abarcó 4 sesiones de 2 horas cada una. Como ya conocían la dinámica, tras los 5 min de dudas, parason a formar los grupos y a trabajar. En ésta sesión se resolvieron las 2 primeras preguntas. Son preguntas que ya les sonaban del bachiller/ciclo por lo que las respondieron bastante amplias. La primera pregunta generó un poco de controversia, entre si las proteínas se clasificaban por su estructura desde el punto de vista espacial o no. Analizando las preguntas siguientes, ellos concluyeron a qué clasificación estructural se refería la pregunta. La segunda pregunta se realizó correctamente y sin mucha controversia. Solo dio tiempo a responder el primer apartado de dicha pregunta. En los últimos minutos de la clase se recordó las siguientes preguntas que tenían que trabajar.

Comenzamos la siguente sesión con la misma dinámica que con las anteriores. Se terminó de responde a la 2o pregunta y continuamos con la tercera. Ésta última fue un gran desastre, se basaron en enumerar similitudes y diferencias entre la Hemoglobina y Mioglobina pero no ahondaron en nada. Se conformaron con lo simple y no buscaron las diferencias bioquímicas. En éste punto tuve que intervenir y recordarles que sin el trabajo previo no había ganancia de conocimiento. Como el tiempo se terminaba, les recordé el trabajo para el próximo día. Noté un poco de cansancio, desgana, no sabría como definirlo. Quizás una dinámica similar varios días termina aburriendo.

La tercera sesión comenzó mucho mas animada, les propuse que cada secretario de grupo salieran y entre ellos comenzaran a responder. Pareció que les gustó mas y las 2 últimas preguntas las respondieron mucho mejor.

La última sesión la utilicé para hacer un resumen de todo lo que se había hablado en las 3 anteriores y aproveché para añadir, si era necesario, algo importante que faltase. Tras el resumen realizamos el juego de Pasapalabra, en el cual todos participaron. Quizás por que había

Jornadas de Formación e Innovación Docente del Profesorado | № 2 (2019)

Esta obra se distribuye con la licencia Creative Commons 
bombones como premio, pero observé la implicación y complicidad entre ellos para resolver cada una de las preguntas.

Por último el tercer CIMA se ha realizado en 2 sesiones de 2 horas cada uno. En la primera sesión iniciamos explicando la dinámica y aunque empezaron a poner pegas por los artículos en ingles, trabajaron todos muy bien. Al ser grupos pequeños, la comunicación entre ellos era fluida, y al no saber quien de ellos expondría el artículo todos trabajaron y compartieron opiniones. En el primer artículo los primeros 30 minutos resultaron muy ajustados, por lo que les di 5 minutos mas para que pudiran concluir. Se eligieron 4 personas al azar, una de cada subgrupo y entre los 4 expusieron el artículo. El objetivo de este CIMA es aprender a enfrentarse a un artículo científico en ingles y saber sacar las ideas principales. Además se pretendía que aprendiesen a colaborar de forma espontánea sin tener que prepararse de antemano nada.

\section{Evaluación del aprendizaje}

Tras la realización de los tres CIMA se analizaron los resultados de aprendizaje de los estudiantes. Para ello se compararon los dos cuestionarios, inicial y final, que contenían las preguntas que posteriormente se habían trabajado durante elciclo. Se han analizado una muestra de 50 cuestionarios individuales, de los 69 que se recogieron. A continuación se muestran las escaleras de conocimiento y aprendizaje correspondientes a las cuestiones mas representativas.

\section{CIMA 1.}

A. ¿Cómo clasificaríamos las siguientes enfermedades según si afectan a tejidos o células o si tienen alteraciones moleculares? ¿Cómo es su herencia?

- Albinismo o Fibrosis quística

Jornadas de Formación e Innovación Docente del Profesorado I № 2 (2019)

Esta obra se distribuye con la licencia Creative Commons 
- Enfermedad de Corea de Huntington

- Distrofia muscular de Duchenne

- Sindrome de X-frágil

El 83\% de los alumnos alcanzan el objetivo de la pregunta: clasificar las diferentes enfermedades según su herencia autosómica o ligada al sexo, dominante o recesiva (figura 5).

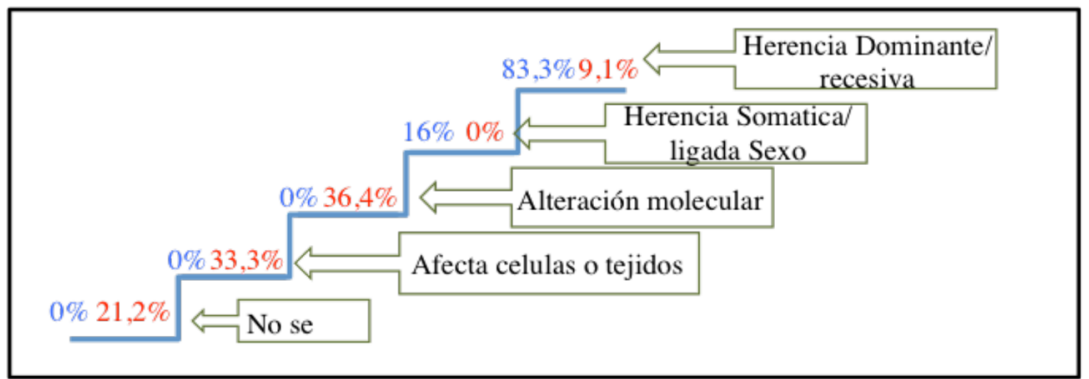

Figura 5. Escalera de aprendizaje CIMA 1.

B. Hay enfermedades cuya afectación molecular es a nivel cromosómico. ¿Influye la localización? ¿Por qué?. Resultados: Casi el $83 \%$ de los alumnos consiguen determinar que las enfermedades moleculares pueden afectar también al DNA mitocondrial y no solo al DNA nuclear (figura 6)

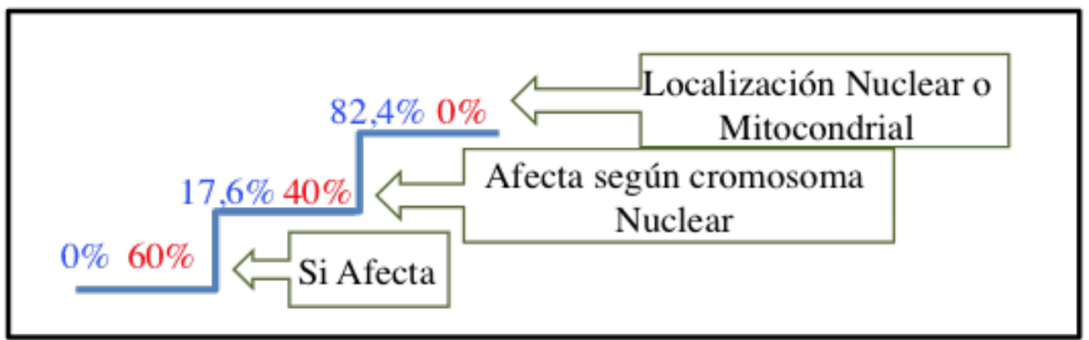

Figura 6. Escalera de aprendizaje CIMA 1.

C. ¿Sabrías decir como se originan las enfermedades cromosómicas? ¿Cómo conocemos la enfermedad de la trisomía del par 21?, ¿sabrías decir alguna característica molecular? Resultados: Tras el CIMA el 100 de los

Jornadas de Formación e Innovación Docente del Profesorado | № 2 (2019)

Esta obra se distribuye con la licencia Creative Commons 
alumnos alcanzaron el objetivo planteado. Saber el origen de las enfermedades cromosómicas y las características de la Trisomía del par 21 o Síndrome de Down (figura 7).

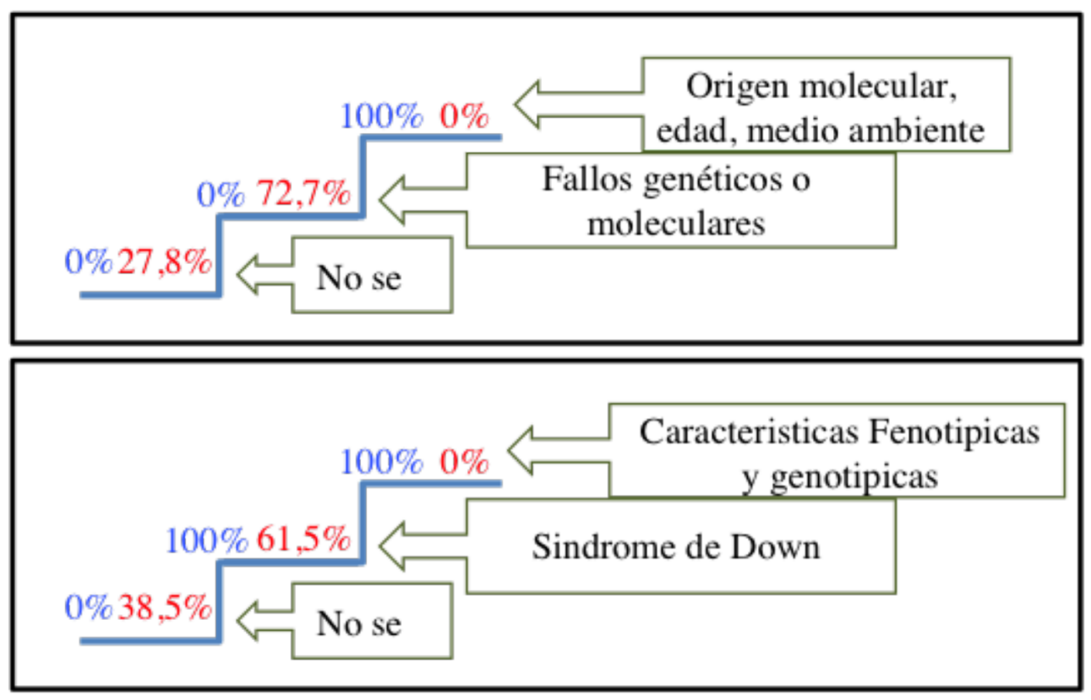

Figura 7. Escalera de aprendizaje CIMA 1. D.

La Terapia génica se conoce como la inserción de elementos funcionales en el genoma de un individuo, ¿sabrías decir por que se utiliza esta técnica?,¿en qué casos se realiza? Resultados: Aunque un porcentaje alto de los alumnos tenían conocimiento del concepto de las Terapias génicas, tras la realización del CIMA 1 comprendieron que técnicas se utilizan y en que casos se pueden aplicar (87,5\%) (figura 8).

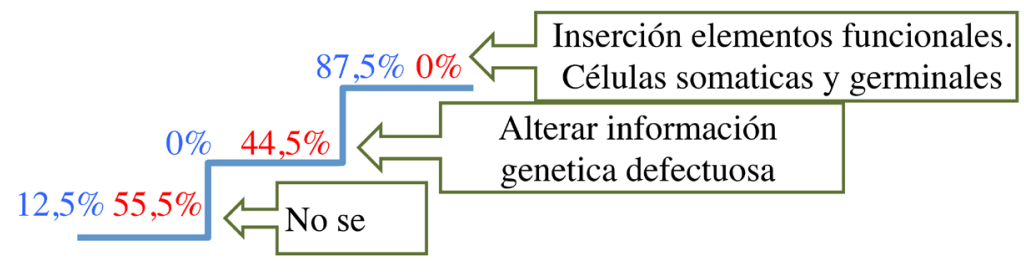

Figura 8. Escalera aprendizaje CIMA 1.

Jornadas de Formación e Innovación Docente del Profesorado | № 2 (2019)

Esta obra se distribuye con la licencia Creative Commons Reconocimiento-NoComercial-SinObraDerivada $\quad 4.0$ Internacional (CC BY-NC-ND 4.0.) 


\section{CIMA 2.}

3. ¿La Mioglobina y la Hemoglobina tienen igual función?, Enumera las similitudes y diferencias. Resultados: Antes de comenzar el CIMA, el 47\% de los estudiantes pensaban que la función de la Hemoglobina era similar a la mioglobina. Tras el ciclo el $98 \%$ tiene claro las diferencias y similitudes de ambas proteínas (figura 9).

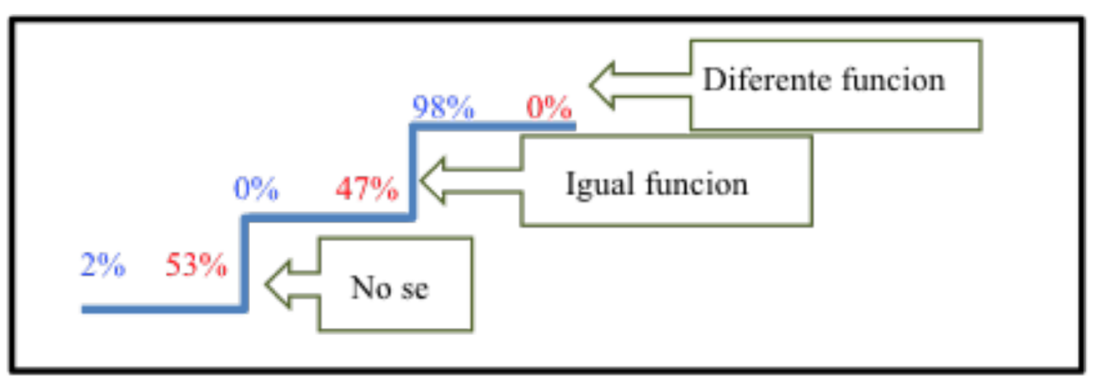

Figura 9. Escalera aprendizaje CIMA 2.

4. El plasma sanguíneo está formado por muchas proteínas con diversas funciones. ¿Sabrías explicar las mas abundantes e importantes? ¿Qué proteína implicada en la defensa del organismo encontramos en el plasma? Resultados: Mas de la mitad de los alumnos no sabían al inicio del CIMA que proteínas forman parte del plasma sanguíneo. Tras el CIMA el 100\% han conseguido identificarlas e incluso definir y carcterizar las Inmunoglobulinas (figura 10).

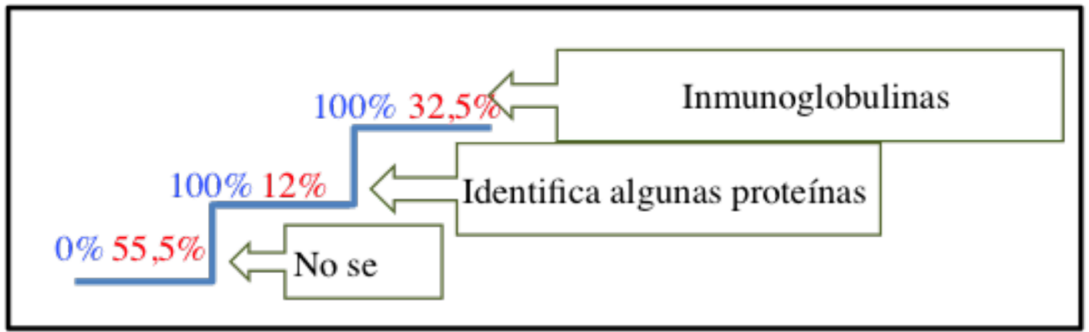

Figura 10. Escalera aprendizaje CIMA 2.

Jornadas de Formación e Innovación Docente del Profesorado | № 2 (2019)

Esta obra se distribuye con la licencia Creative Commons 


\section{CIMA 3.}

En este caso no se ha hecho una escalera de aprendizaje sino se les ha pasado un cuestionario que determine la capacidad de enfrentarse a otro idioma que no sea el nativo, la capacidad de trabajo en grupo y su capacidad de improvisación. A continuación se expone el cuestionario y los resultados. El primer porcentaje se corresponde con el cuestionario inicial y el segundo con el final (negrita).

1. ¿Tiene conocimientos sobre como analizar un artículo de investigación?

Valore de 1 (nada) a 5 (mucho) los conocimientos que tiene de esta pregunta

\begin{tabular}{|l|l|l|l|l|}
\hline 1. Nada & 2.Casi nada & 3. Algo & 4. Bastante & 5. Mucho \\
\hline $0 \% / \mathbf{0} \%$ & $0 \% / \mathbf{0} \%$ & $75 \% / \mathbf{1 0} \%$ & $25 \% / \mathbf{9 0} \%$ & $0 \% / \mathbf{0} \%$ \\
\hline
\end{tabular}

2. ¿Sabría obtener los conceptos fundamentales de un artículo científico?

Valore de 1 (nada) a 5 (mucho) los conocimientos que tiene de esta pregunta

\begin{tabular}{|l|l|l|l|l|}
\hline 1. Nada & 2.Casi nada & 3. Algo & 4. Bastante & 5. Mucho \\
\hline $0 \% / \mathbf{0} \%$ & $83 \% / \mathbf{0} \%$ & $17 \% / \mathbf{1 2} \%$ & $0 \% / \mathbf{8 8} \%$ & $0 \% / \mathbf{0} \%$ \\
\hline
\end{tabular}

3. ¿Podrías explicar junto a varios compañeros un tema específico sin antes hacer un reparto de dicho tema?

\begin{tabular}{|l|l|l|l|l|}
\hline 1. Nada & 2.Casi nada & 3. Algo & 4. Bastante & 5. Mucho \\
\hline $0 \% / \mathbf{0} \%$ & $0 \% / \mathbf{0} \%$ & $67 \% / \mathbf{0} \%$ & $33 \% / \mathbf{1 0 0} \%$ & $0 \% / \mathbf{0} \%$ \\
\hline
\end{tabular}

Jornadas de Formación e Innovación Docente del Profesorado | № 2 (2019)

Esta obra se distribuye con la licencia Creative Commons 


\section{Evaluación del CIMA}

\section{Cuestiones a mantener y cambios a introducir}

Para la evaluación del CIMA se ha empleado la observación directa de los estudiantes y el cuaderno de campo. En este se ha anotado como se han desarrollado cada una de las actividades que se han realizado, al igual que las impresiones percibidas. Además, al finalizar la última sesión se les distribuyó un cuestionario de satisfacción. El $56 \%$ de los alumnos están muy satisfechos con el método docente empleado. El dinamismo de las clases y aportar sus propios conocimientos aunque sean cuestionados, les parece un aspecto a seguir manteniendo. Hacer un repaso final de todo lo dicho durante las sesiones, interviniendo tanto el profesor como los alumnos, es otra de las medidas a mantener. El CIMA 3, aunque les generó muchos problemas inicialmente por el idioma, al final han valorado con un $87 \%$ estar bastante satisfechos. Han sabido solventar la barrera del idioma y han sabido compenetrarse para permitir que todos participaran de forma equilibrada.

El tiempo para realizar el segundo cuestionario, es corto, por lo que plasmar los conocimientos adquiridos en solo 15 o 20 min no es suficiente. Para nuevos CIMA, ampliaré dicho tiempo para que ellos se den cuenta del conocimiento que han adquirido durante las diferentes sesiones.

\section{Aspectos a incorporar a toda la práctica docente}

Me quedo con la gran participación de lo estudiantes y el interés por resolver los problemas planteados. La participación no sólo se ha observado en el trabajo fuera del aula, sino también, en sus intervenciones en clase y las discusiones generadas entre ellos. El detalle de no coger

Jornadas de Formación e Innovación Docente del Profesorado | № 2 (2019) 
apuntes mientras hago el resumen, me ha demostrado que la asimilación de los conceptos ha sido amplia y que han sabido conectar la pregunta con la respuesta. Quiero seguir incluyendo la dinámica del trabajo fuera del aula y después en clase aunque intentaré variar las actividades para evitar entrar en monotonía. He visto que ser ellos parte activa les motiva y esto hace que todo sea dinámico y sencillo. Estoy muy contenta con el resultado.

Jornadas de Formación e Innovación Docente del Profesorado | № 2 (2019)

Esta obra se distribuye con la licencia Creative Commons 


\section{Referencias bibliográficas}

Finkel, D. (2000). Teaching with your mouth shut. Portsmouth, NH. HeinemannBoynton/ Cook. (Trad. Ast.: Dar clase con la boca cerrada. Valencia. Publicaciones de la Universidad de Valencia, 2008).

Amador, L., Monreal, M.C. y Marco, M.J. (2001). El adulto: etapas y consideraciones para el aprendizaje. Eúphoros, 3, 97-112.

Porlán, R. (Coord), Vázquez, J., Solís, E., Martín, R., Pineda, J. A., Duarte, O., De Alba, N., García, E., Navarro, E., Rivero, A., García, F. F., Feria, B., GuerraMartinn, M. D., Fuentes, A., Mora, J. P. y Herrera, J. A. (2017). Enseñanza universitaria. Cómo mejorarla. Ediciones Morata. Sevilla.

Jornadas de Formación e Innovación Docente del Profesorado | № 2 (2019)

Esta obra se distribuye con la licencia Creative Commons 